\title{
Secured Administration and Management of Pertinent Data based on Web Technology and Data Mining
}

\author{
Z. A. Usmani, Saiqa Khan, Mustafa Kazi, Aadil Bhatkar, Shuaib Shaikh \\ Computer Engg Dept., MHSSCOE \\ Mumbai, INDIA.
}

\begin{abstract}
Automation has gained universal popularity these days. This paper lays emphasis on a web-based department automation system which is currently under development process and is primarily aimed at keeping track of faculty details and records. Also, another fundamental aspect considered is the reduction of overall paperwork involved. The application is designed at providing systematic, well planned and well organized working environment for the faculty of institution. Concept of modern-day technologies like data mining and web technology are the understructure of the system. The system focuses at overcoming the drawback of existing method by reducing errors and mistakes in record keeping as data is stored digitally. Computation of queries is processed swiftly to fetch data from a massive database. The application is designed using Eclipse (kepler version), Apache Tomcat server 7.0 along with wamp server to host the database locally. J2EE, JSP along with $\mathrm{Html}$ have been used for designing the user interface whereas MySQL database is used for storing data.
\end{abstract}

\section{Keywords}

Automation, Web Technology, Data Mining, J2EE, MySQL, Faculty

\section{INTRODUCTION}

Data mining is one of the most booming technologies in the current digitalized era. The approach adopted at present is the traditional approach in which data is stored in physical files and folders for record keeping and maintenance. Due to this there is a possibility of loss of pertinent and pivotal information of the institution. Also there are chances of misplacing the files which may contain confidential data of the institution or information related to faculty or students. Distinctly, an automated system that can maintain and keep track of data and information digitally is required for improvised and efficient working of the organization. It not only improves the overall efficiency of the institution but also it reduces the amount of paper work involved. Gradually, reducing the overall cost of stationary to the institution and minimising the prospect of making mistakes and errors. The shortcomings of existing approach cannot match up with the rapid and ever changing requirement of educational sector. The major points which need to be addressed are mainly briefed as follows:

(1) Accessing the data is a strenuous and weary process as the faculty has to go through a pile of files and bunches of folder to get the relevant information.

(2) Any form of data or information of faculty or student is of great value to the respective educational institution and hence it becomes imperative to store it in digital format.
(3) Manual retrieval and extraction of data is a very time consuming process.

(4) Faculty has to go through bunches of folder and piles of paper for the sole purpose of maintaining and updating student records.

With a view of overcoming the difficulties faced by faculties of institution a systematic, well-planned and well organized system is required which can:

(1) Reduce the amount of paperwork a faculty has to go through for accessing and updating records.

(2) Provide information related to faculty such as their achievement, publications etc. is stored in electronic format and is easily available in PDF format.

(3) Shorten the amount of time needed for acquiring information and keeping intact the consistency and integrity of the data.

(4) Swiftly provide and access the required information from the database digitally.

With the planned implementation of this system at department level will not only reduce the efforts and time required by faculty for keeping track of data but also will distinctly reduce the amount of monetary cost to the institution .Thus, on a broader level, successful implementation of this system will make the process of storing and accessing data much more convenient along with the improved level of security of data.The remaining section of this paper is categorized as follows: Section II represents the literature survey. Section III briefs about proposed architecture and modular description for department automation system. Section IV elaborates the implementation and experimental details of the proposed system prototype. Section V aims at the discussions and results obtained through this research paper. Finally, Section VI provides conclusions and possible future research directions.

\section{LITERATURE SURVEY}

This literature survey aims to identify the shortcomings of automation process proposed by other researchers in the field of education. Our focal point would be to automate the current existing approach used at the departmental level of educational institutions using the concept of data mining as the under structure. The department of an educational organization is vast and several components together make up the entire department which is required for smooth functioning of the said organization. The several previous studies [1,2 and 3] focused on the possibilities of automating these components individually. The scope of the proposed system is the broader level implementation of automation process. The basic plan of designing a department automation system emerged through the observation and in-depth study of research paper published by Husin.J Then et al. [1]. Payroll system was proposed which consisted of multiple components and was hence led to a very mammoth and tedious 
management process as depicted by Husin.J Then et al. [1].In a very similar context, automation of a department is huge cluster of data related to faculty and students and their achievements. As mentioned in the above section of this research paper, it is distinctly clear that a department is made up of a number of modules which need to be automated for systematic, well-balanced and cost effective for the effective functioning of the educational organization. Without a doubt, there is an substantial need for department to automated in to order to match the changing requirements of the digital world. Attendance management of student was proposed by Zonggang et al. [2]. Providing the complete and detailed records of student was proposed by the author Zonggang et al [2] through a web-based application. The user of the system can generate the report of attendance and use it according to their role in organization viz. teacher or counsellor. They tackled the drawback associated with the ever increasing number of students and the need of software to overcome the stated problem. However, in the said proposed system authors solely lay emphasis on attendance aspect of the discussed issue and not paying much heed to other various complications emerging due to the upsurge in the number of students. Some important points which could be noticed are as follows:

(1) No functionality to keep track of student information such as personal data, academic information and extra-curricular activities.

(2) Lack of information about the faculty working in that educational institution.

(3) Information about the student already passed out from the organization, whether working or pursuing higher studies

Clearly, it is quite visible from the survey that the proposed system was lacking few crucial aspects which needed to be followed up. Similarly, Ivankovic et al. [3] puts forward the concept of developing an application which has the ability to handle the monotonous procedure required for publishing a book through library. The proposed system aimed at designing system software that can change the conventional old school procedure with regard to a library. The author at [3] planned of implementing a system which was able to keep information on the check in and check out of the books and magazines from library which would help reduce the time consumed for such unexciting laborious process. Also, authors suggested that the system software can provide data regarding the book funds of the library and generate reports for proper functioning of library. The proposed system is no doubt a competent design, however it would be much more effective and encouraging for the faculty as well the management of the institute if the system application is accomplished enough for providing details related to the publications of faculty as well as students. On the basis of these inspection and studies a module is proposed in our system that can:

(1) Access and display details of international conference papers as well as national conference published by the faculty as well as the students of that educational institution.

(2) Provide information about the reference books and textbook published by the faculty of that institute along with other technical details of the book.

(3) An option to save the information obtained from the above said functionalities regarding the papers and publications of books in the form of PDF.
(4) Display and print the details related to the author or publisher of the book or international paper or national paper.

The literature survey makes it quite evident that neither of the research in the past targeted towards automation of a whole department based on the concept of data mining and web technology. To the best of our knowledge, several authors [2 and 3] in the recent past have emphasized the need of a system that can automate the procedures of an educational organization viz. university or college. However this previously reported work substantiated at implementing it independently, whereas there is a need of a web-based application that perform department automation on whole and perform various functionalities and tasks as required at educational institution level. Thus there is a need of an independent department automation system that fulfils the requirements of current scenario and works towards invaluable contribution to the research community.

\section{PROPOSED ARCHITECTURE \& MODULAR DESCRIPTION}

\subsection{Architecture:}

At present the proposed system is aimed at automation of a single department, therefore it will be based on a peer to peer distributed architecture model. All the peers will be equally privileged to access the data. Each of them will be an equipotent participant in the entire architecture.

The following figure depicts a model of peer to peer distributed architecture.

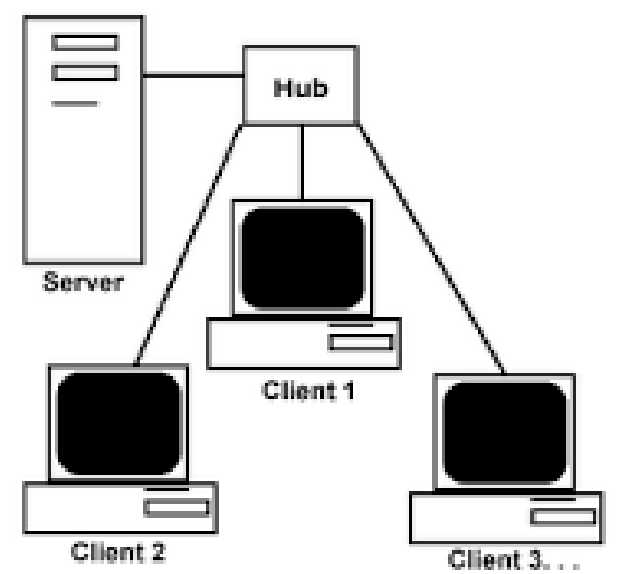

Fig.1 Peer to Peer Architecture

\subsection{Modular Description:}

Functioning of every department in an organization follows a specific approach which subdivides the department into viable working modules. These modules are rigorous, well defined and discretely scalable providing flexibility in designing and augmentation of the system.

Based on the MVC approach, the proposed system is categorized into following modules:

\footnotetext{
1. Faculty \& Student Publications

2. Faculty \& Student Achievements

3. Faculty Professional Details

4. Student Entrepreneurship Details

5. Student Higher Study Details
} 
The brief description about each module is given in the following sections.

\section{Faculty \& Student Publications:}

All the data and details related to the publication work of faculties and students will be contained in this module.

\section{Faculty \& Student Achievements:}

Faculties and students receive many laurels and awards during their academic and professional life. These details will be stored under faculty and student achievement module.

3. Faculty Professional Details:

All the professional details of faculties working in the institution will be stored in Faculty Professional Details module.

4. Student Entrepreneurship Details:

Many students in their academic career come up with ideas of start-up companies. The details related to their registered start-ups will be available under this module.

\section{Student Higher Study Details:}

The details of students opting for higher studies will be incorporated in higher study module.

\section{IMPLEMENTATION DETAILS}

\subsection{Software Tools Used}

A web based application will be developed for the proposed system using the following software development tools:

- $\quad$ Eclipse (Kepler Version)

- Apache Tomcat server 7.0

- Wamp Server

The above mentioned software tools will help in designing software specifications of the system in a modular fashion as discussed in section III pertaining to the current needs of the industry.

\subsection{User Interface Designs:}

The following figures give an insight to the web application interface which is developed using the relevant tools.

\section{LOGIN}

\section{$\mathrm{Hi}$,} Welcome, please login.

Username

Password

$\log$ in $\rightarrow$

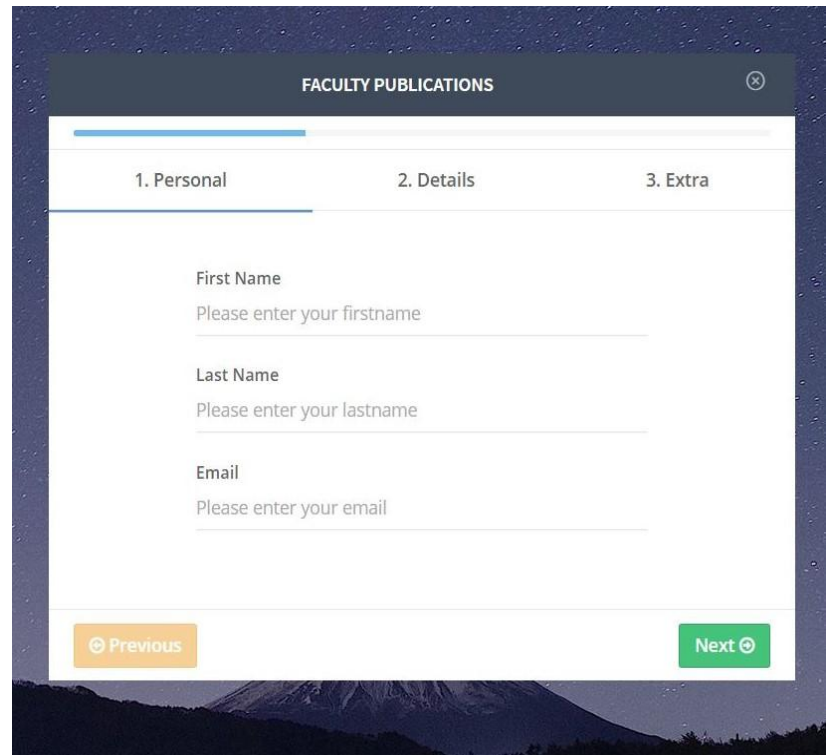

Fig.3 Faculty Publication

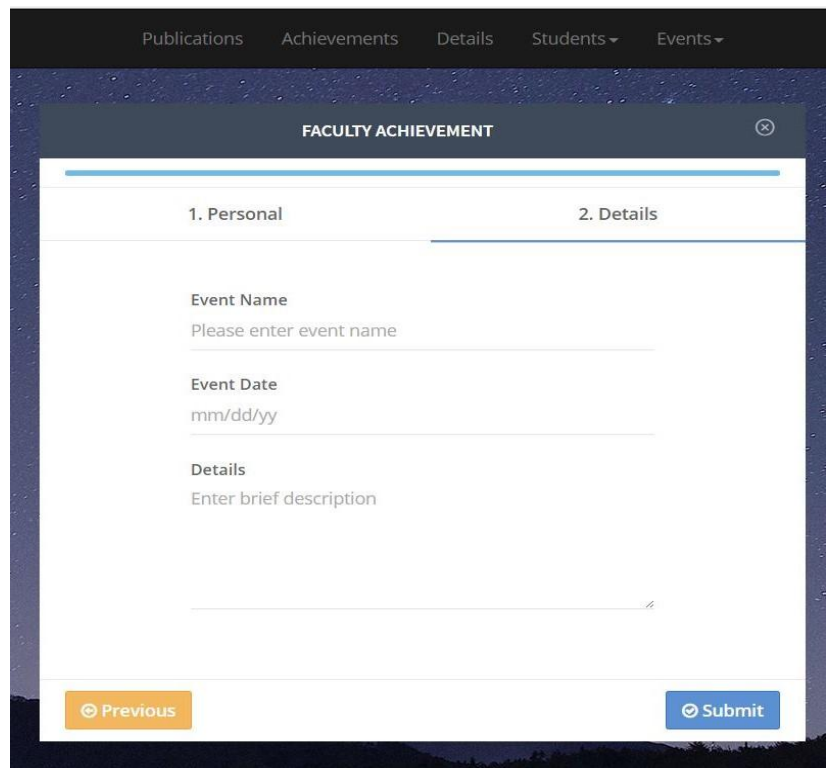

Fig.4 Faculty Achievement

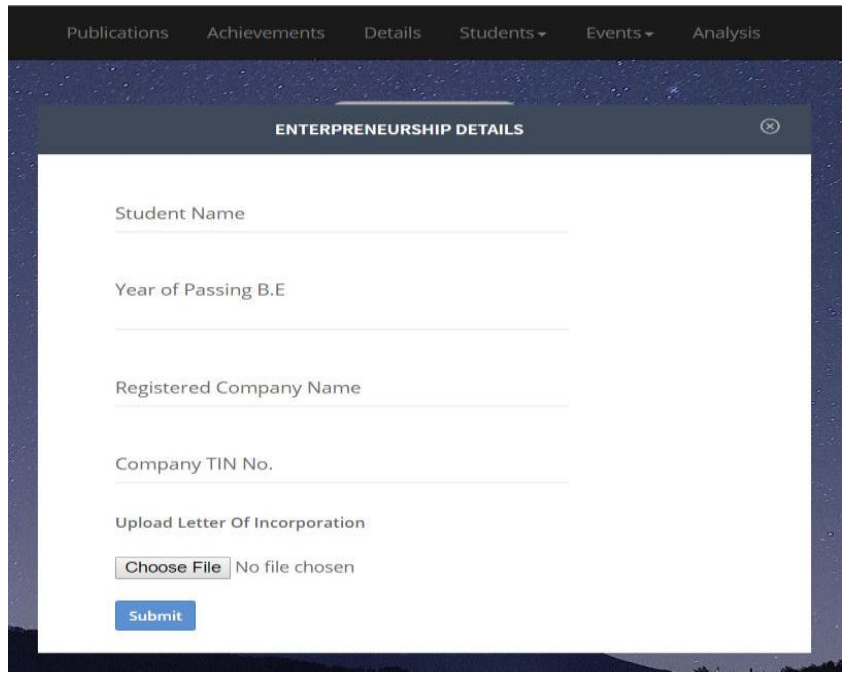

Fig.5 Student Entrepreneurship Details

Fig.2 Login Wizard 


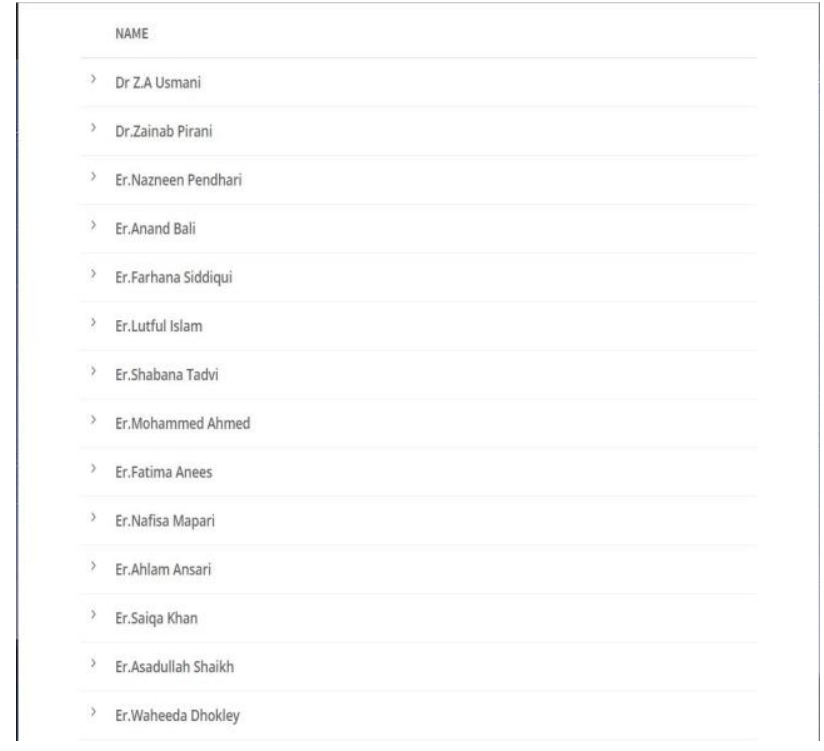

Fig.6 Search based on Faculty name

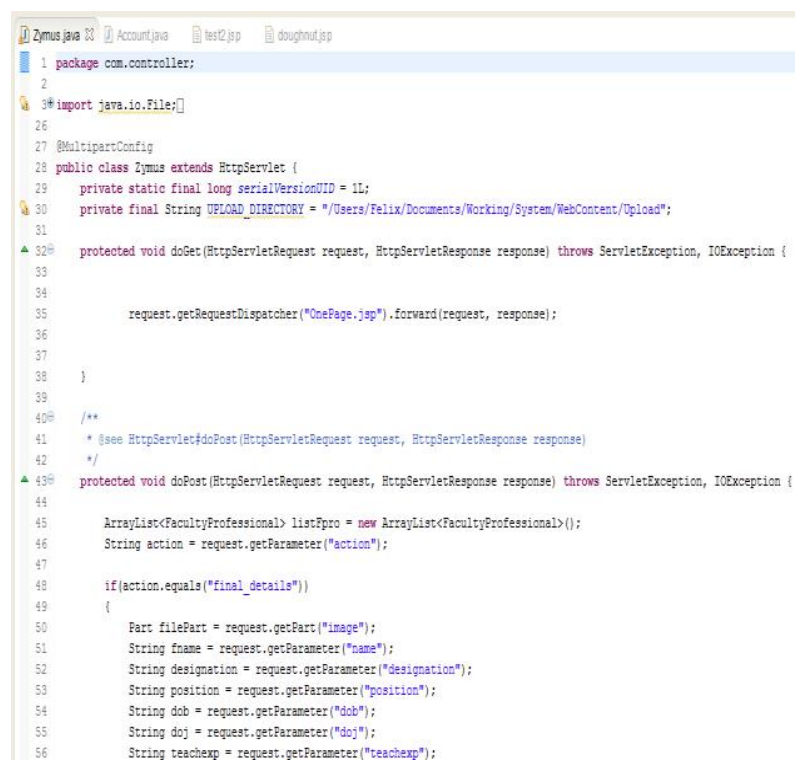

Fig.7 Implementation code 1

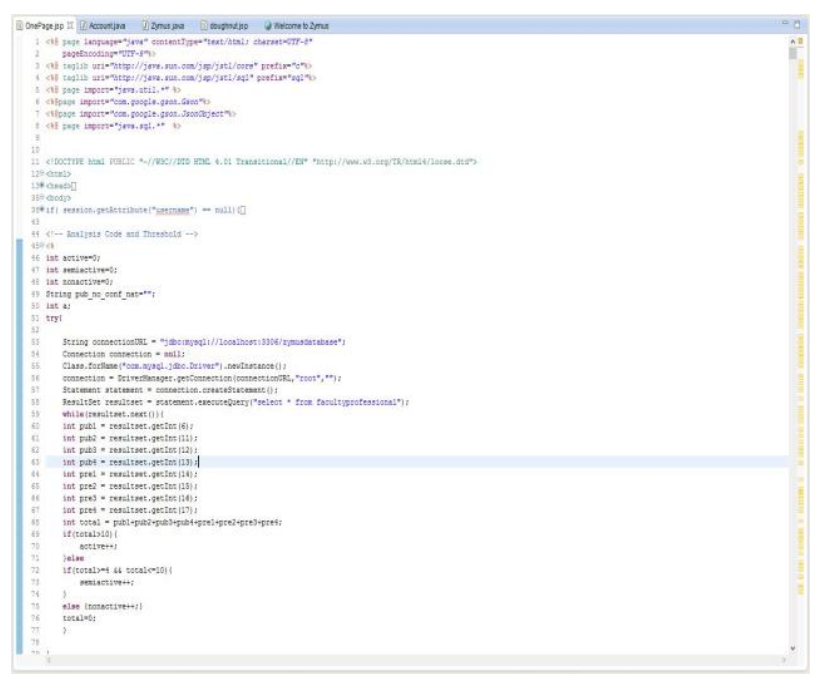

Fig.8 Implementation code 2

\section{RESULTS \& DISCUSSIONS}

A detailed study and analysis of various related automation systems with our proposed system, led to a comparison of efficiency parameters towards computation and retrieval of required data. The same can be depicted with the bar graph as follows:

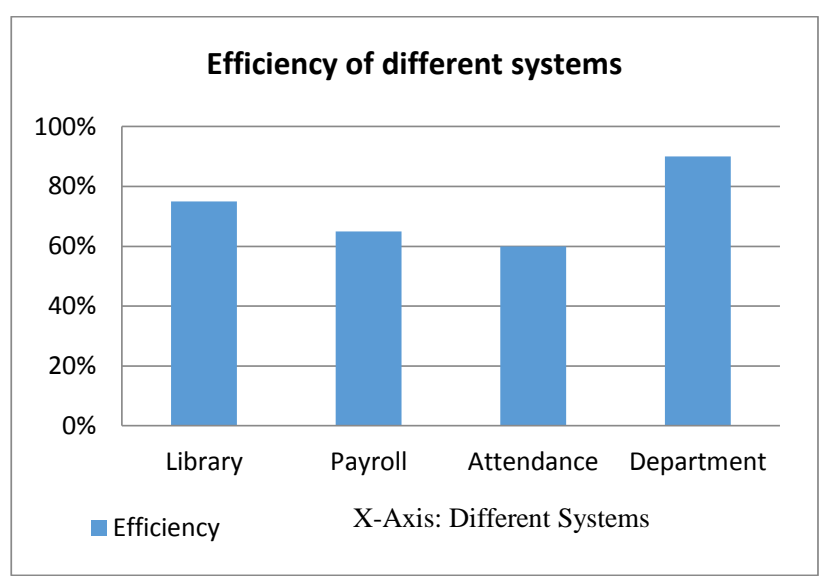

Fig.9 Comparison of different systems based on efficiency

The plot of above bar graph shows efficiency of different systems based on their query calculation time. It can be clearly observed that the proposed system is highly efficient compared to other similar automated systems in terms of data processing.

Moreover, an observational study on parameters of report generation, availability of overall system and user-friendliness of different systems can be summarized as under:

Table.1 Comparison of different systems based on different parameters

\begin{tabular}{|l|c|c|c|}
\hline \multicolumn{1}{|c|}{ Systems } & $\begin{array}{c}\text { Report } \\
\text { Generation } \\
\text { level }\end{array}$ & $\begin{array}{c}\text { Availability } \\
\text { of the system }\end{array}$ & $\begin{array}{c}\text { User } \\
\text { friendliness } \\
\text { level }\end{array}$ \\
\hline Library [3] & Good & Good & Average \\
\hline Payroll [1] & Good & Average & Low \\
\hline $\begin{array}{l}\text { Attendance } \\
{[2]}\end{array}$ & $\begin{array}{c}\text { No such } \\
\text { option }\end{array}$ & Average & High \\
\hline Department & Very good & Good & High \\
\hline
\end{tabular}

Report generation: Reports related to professional details of faculties, their academic and professional achievements, event reports and student details will be generated. Computation and generation of reports in department automation system is comparatively better than other systems.

Availability of the system: The automated system will be available to all the authorized users round the clock and accessible through different computing platforms and devices.

User-friendliness: Ease of access to all kind of users through simple and interactive interface. Even naïve users with very low computer proficiency can work on it. 


\subsection{Comparison with existing approach:}

Table.2 Comparison of manual and automated approach

\begin{tabular}{|c|c|c|}
\hline Approach & $\begin{array}{c}\text { Information } \\
\text { Accessibility }\end{array}$ & $\begin{array}{c}\text { Database } \\
\text { Maintenance }\end{array}$ \\
\hline Manual & Slow & Difficult \\
\hline Automation & Very fast & Easy \\
\hline
\end{tabular}

The current manual approach used involves tremendous paperwork for maintaining the records and database. In the present approach there is a possibility of loss of data through various unaccustomed reasons. On other hand, the new proposed approach will contribute towards data management and safety as the database will be digitized, replicated and fragmented at various locations if necessary. Also the traditional approach requires manual searching and processing of data which is time consuming compared to automated approach where data is available on demand with just a few key strokes.

One of the key features of the new proposed system is the activity analysis graph of faculties. This graph will give an overall gist about how many faculties are active, semi-active and non-active which will help in offering appraisals and rewards to the faculties.

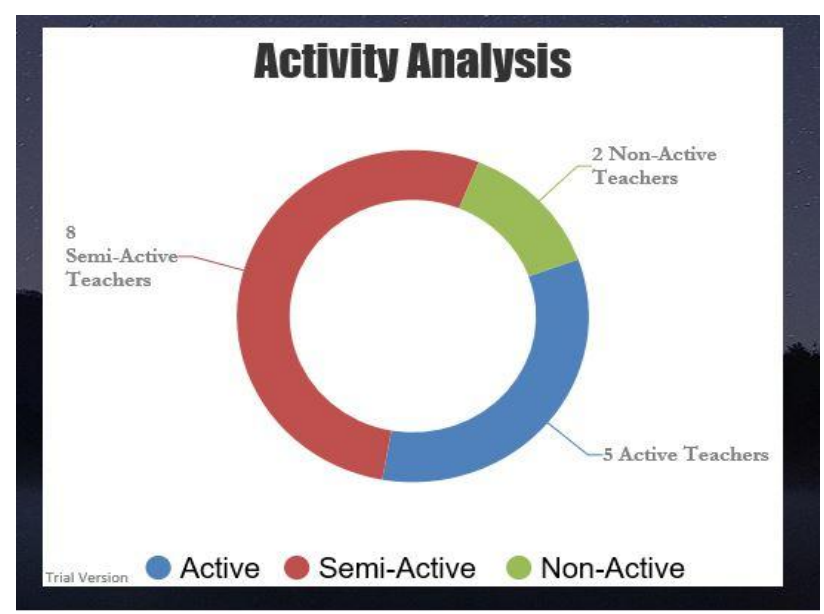

Fig.10 Faculty Activity Log

The activity analysis graph shown above will be implemented using Apriori Algorithm for report generation as follows:

1. Read data from database (Number of papers published, workshops attended)

2. Set a threshold value.

3. Compare each faculty's data against the threshold value.

4. The faculties who published papers greater than that of threshold are active and those below the threshold value are non-active.

5. Generate reports based on the above analysis.

6. Based on the generated reports develop a statistical pie chart classifying the percentage of active, semiactive and non-active faculties.

\section{CONCLUSION}

In this paper the implementation of department automation system has been discussed. The system has been implemented using the web technology. The concept of data mining has been used to generate reports based on faculty activity in the department. The system has been tested and deployed in the campus. Personal as well as professional information related to the faculties can be easily accessed on the system. Future scope involves the incorporation of student module in the system.

\section{REFERENCES}

[1] Analysis, Design and Implementation of a WebBased Payroll Application Software Husin J. Then; Biju Issac; Lau T. Chung; Susanti Wongso; Riyan Bong; Lesley Lu; Yu P. Ling Computer Technology and Development, 2009. ICCTD '09. International Conference on Year: 2009, Volume: 1

[2] Design and Implementation of Student Attendance Management System Based on MVC Zonggang He; Junsheng Zheng Management and Service Science, 2009.MASS '09. International Conference on Year: 2009

[3] Realization of school library software application Zdravko Ivankovic; Branko Markoski; Ivana Berkovic; Dragan Ivetie 2009 7th International Symposium on Intelligent Systems and Informatics Year: 2009

[4] Study on library automation management system of SaaS Bo Zhou; Wenliang Liu Computer Science and Network Technology (ICCSNT), 2013 3rd International Conference on Year: 2013

[5] Application of Business Intelligence: A Case on Payroll Management Monika Arora; Deepankar Chakrabarti Computational and Business Intelligence (ISCBI), 2013 International Symposium on Year: 2013

[6] Automation of decision making process for selection of talented manpower considering risk factor: A data mining approach Mohd Mahmood Ali; Lakshmi Rajamani Information Retrieval \& Knowledge Management (CAMP), 2012 International Conference on Year: 2012

[7] The application of Apriori-BSO algorithms in medical records data mining Wang Renli; Dai Yueming; Dong Liming 2016 IEEE Information Technology, Networking, Electronic and Automation Control Conference Year: 2016

[8] Educational data mining to track students performance on teaching learning environment LabSQL Azauri S. Figueira; Amanda S. Lino; S. S. Paulo; Clayton A. M. Santos; Tânia S. A. Brasileiro; Adriano Del Pino Lino 2015 10th Iberian Conference on Information Systems and Technologies (CISTI) Year: 2015

[9] Data Mining: What is Data Mining? http://www.anderson.ucla.edu/faculty/jason.frand/teacher /technologies/palace/datamining.htm 12-09-2016 15.30 IST

[10] Automation https://en.wikipedia.org/wiki/Automation 12-09-2016 17.07 IST

[11] Design $\quad$ Patterns: $\quad$ MVC Pattern http://www.tutorialspoint.com/design_pattern/mvc_patte rn.htm 13-09-2016 10.40 IST 